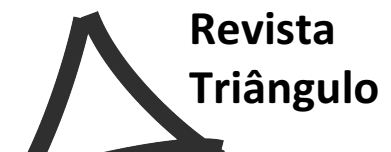

\section{O PERFIL DOS CURSISTAS DE UMA AÇÃO DE FORMAÇÃO CONTINUADA}

\author{
THE STUDENTS PROFILE OF STUDENTS OF A CONTINUING EDUCATION \\ ACTION
}

\author{
Maira dos Santos Mussato ${ }^{1}$ e Regina Maria Rovigati Simões ${ }^{2}$
}

\begin{abstract}
RESUMO
O objetivo foi caracterizar o perfil e verificar como ocorreu o interesse pelo curso de Aperfeiçoamento Educação Integral: Expressões verbais e corporais, oferecido pela Universidade Federal do Triângulo Mineiro - UFTM vinculado ao Programa Mais Educação da SEB/MEC. Para tal, foi aplicado um questionário a 56 cursistas, que além de identifica-los verificou como ocorreu a participação. Os resultados mostraram que dois são homens e tem idade entre 20 e 60 anos. A maior parte tem menos de cinco anos de formados, porém $55 \%$ deles já havia participado de algum curso de Formação Continuada. Um dado relevante é que a maioria frequentou o curso de forma espontânea (82\%), em detrimento de $18 \%$ que participaram por incentivo, obrigação ou motivo não revelado. É de conhecimento geral a necessidade da formação continuada na carreira docente e diante da complexidade que é abordagem dessa busca pelos profissionais docentes devemos tentar estimular com essas discussões a necessidade de capacitação especial para atuação na Escola de Tempo Integral, para que haja o real comprometimento com a formação integral do aluno.
\end{abstract}

PALAVRAS-CHAVE: Formação continuada. Educação integral. Programa mais educação. Professor.

\begin{abstract}
The objective was to characterize the profile and see how was the interest in the course of Improvement Integral Education: verbal and bodily expressions offered by the Federal University of Triangulo Mineiro - UFTM linked to the More Education Program of SEB / MEC. To this end, a questionnaire was applied to 56 course participants, which in addition to identify them as there was participation. The results show that two are men and is aged between 20 and 60 years. Most have less than five years of graduation, but 55\% of them had already participated in a course of Continuing Education. A relevant fact is that the majority attended the course spontaneously (82\%), over 18\% who participated in incentive, obligation or undisclosed reason. It is well known the need for continuing education in the teaching career and given the complexity that is approach this search by professional teachers should try stimulate these discussions with the need for special training to operate in full Time School, so there is real commitment to the integral formation of the student.
\end{abstract}

KEYWORDS: Continuing Education. Comprehensive education. Program more education. Teacher.

\section{INTRODUÇÃO}

Ser professor não é apenas professar um conhecimento, não é somente transmiti-lo, é uma postura, uma vivência do saber, internalização e transformação do conhecimento, preocupação não apenas em formar para o conteúdo, e sim para os aprendizados da vida, sem

\footnotetext{
${ }^{1}$ Programa de Pós-Graduação em Educação. Universidade Federal do Triângulo Mineiro - UFTM e Núcleo de Estudos e Pesquisas em Corporeidade e Pedagogia do Movimento - NUCORPO. Email: maira.smussato@gmail.com

${ }^{2}$ Docente do Programa de Pós-Graduação em Educação e em Educação Física. Universidade Federal do Triângulo Mineiro - UFTM e Núcleo de Estudos e Pesquisas em Corporeidade e Pedagogia do Movimento NUCORPO. Email: reginasimoes58@gmail.com
} 
que o conteúdo deixe de garantir seu primordial espaço. Alguém que julga uma aula boa apenas pelo conhecimento do professor ou pelo que consegue aprender com ele, para nós não está levando em conta todo o processo de ensino aprendizagem.

Segundo Imbernón (2009) a formação dos docentes deve voltar-se para que estes se posicionem enquanto facilitadores da aprendizagem, adeptos de uma prática reflexiva, provocando cooperação e participação dos alunos. O autor ainda defende que a reflexão deve "[...] permitir que examinem as teorias implícitas, seus esquemas de funcionamento, suas atitudes e, sobretudo, realizando um processo constante de auto avaliação que oriente seu trabalho" (IMBERNÓN, 2009, p. 48 e 49).

A necessidade de termos uma identidade formada vem para reafirmar nossos valores, termos direitos garantidos e, principalmente, para que os próprios professores reconheçam sua importância na sociedade. Para que a fala de que "qualquer um pode ser professor" seja extinguida, uma vez que há, inclusive, profissionais da área que se apropriam dessa ideia errônea.

A formação docente segundo Saviani (2008, p. 177) também está relacionada com o desenvolvimento organizacional da escola, e com sua transformação. Por ser esta "a ideia central da vertente leiga da concepção tradicional, isto é, a transformação, pela escola, dos indivíduos ignorantes em cidadãos esclarecidos". Neste aspecto, é necessário, segundo o autor, integrar os conteúdos acadêmicos e disciplinares com a formação do professor, de modo a estruturar a ação pedagógica.

Devido às atividades que tiveram de ser acumuladas às tarefas já exercidas, nos últimos anos Imbernón (2009, p. 14) assevera que a profissão docente, atualmente, não exerce apenas o papel de mediação de conhecimentos, como também “[...] motivação, luta contra a exclusão social, participação, animação de grupos, relação com estruturas sociais e com a comunidade." O que segundo ele requer uma Formação Inicial e permanente, não apenas voltada para o ensino e atualização científica, mas que se situe enquanto espaço participativo e reflexivo, para que os sujeito se adaptem a conviver com mudanças e incertezas.

Ponte (1998) diferencia formação de desenvolvimento profissional. A princípio porque formação se refere a cursos, enquanto o desenvolvimento pode ocorrer em diferentes situações.

Segundo o autor a formação o professor assimila os conteúdos, num movimento de fora para dentro, enquanto no desenvolvimento ele decide o quê e de qual modo quer executar, ou seja, de dentro para fora. A formação trabalha com as dificuldades do 
profissional, porém de modo fragmentado e teórico. Enquanto o desenvolvimento nas palavras de Ponte (1998) enfoca nas potencialidades do sujeito, por meio de seus aspectos cognitivos, afetivos e relacionais, sempre interligando teoria e prática.

Ao passo que Imbernón (2009) defende o desenvolvimento profissional não apenas como desenvolvimento pedagógico, conhecimento e compreensão de si mesmo, desenvolvimento teórico ou cognitivo e sim todos esses desenvolvimentos concomitantemente, afirmando:

[...] considerar o desenvolvimento profissional mais além das práticas de formação e vinculá-lo a fatores não formativos e sim profissionais supõe uma redefinição importante. Significa também analisar a formação como elemento de estímulo e de luta pelas melhorias sociais e profissionais e como promotora do estabelecimento de novos modelos relacionais na prática da formação e das relações de trabalho (IMBERNÓN, 2009, p.47)

No desenvolvimento o professor não é sujeito da formação, pois segundo Ponte (1998) sua individualidade é considerada, ele não é enquadrado a um grupo pertencente. Assim, o autor salienta que não há incompatibilidade entre formação e desenvolvimento, mas sim que um favorece o outro, pois, a eficiência do profissional, não está segundo ele somente no domínio dos conhecimentos proporcionados pela formação, mas também na capacidade de resolução dos problemas práticos adquiridos no desenvolvimento profissional.

Nesse âmbito Teixeira, Silva e Lima (2010) afirmam que o desenvolvimento profissional docente não ocorre de maneira individualizada ou neutra, mas em uma organização abrangente pessoal, curricular e institucional, que reconhece a multiplicidade das ações do professor, enquanto sujeito que contribui para mudanças socioeducacionais.

Nesse âmbito, gostaríamos de destacar as palavras de Imbernón (2009, p. 44-5) em que afirma que a formação permanente:

[...] deveria fomentar o desenvolvimento pessoal, profissional e institucional do professorado potencializando um trabalho colaborativo oara transformar a prática. Parece fácil dizer isso, mas como é difícil mudar as políticas e práticas de formação. Isso implica fugir de políticas de subsídio, de políticas em que se acredita que oferecendo (ou investindo) à formação uma grande quantidade de cursos, seminários ou jornadas, a educação mudará. Deixa-se o contexto trabalhista empobrecido, assim como a metodologia de trabalho da prática formativa mais orientada a praticas formativas 
individuais que a modelos de formação permanente de caráter coletivo, de desenvolvimento e de melhoria do currículo e a processos indagativos em que a base não é a "ignorância do mestre", mas que se confia na capacidade do professorado para gerar inovações através da prática educativa.

Nos anos noventa do século passado, para se adequar à globalização, muitas reformas aconteceram, como exigência de nível superior para atuar em sala de aula, alegando que somente na universidade os professores têm condições de aprofundar os conhecimentos e domínio para exercer a função docente (ALVARADO-PRADA; FREITAS; FREITAS, 2010). Além disso, a Lei de Diretrizes e Bases de 96 exigia nível superior em licenciatura ou normal superior para a atuação, e a data limite para essa regularização foi até 2007.

Neste âmbito, a proposta de educação permanente se intensifica e o tema Formação Continuada passa a compor as discussões educacionais brasileiras, trazendo segundo Silva (2011) questionamentos sobre o professor reflexivo, trabalho coletivo, troca de experiências. Além disto, segundo a autora as formações passam a centrar-se nas escolas em que os professores atuam, o que acaba efetivando as parcerias entre escolas e universidades, atribuindo à última o papel de gerir a Formação Continuada dos professores.

[...] corresponde a uma fase de formação permanente, incluindo todas as atividades planejadas pelas instituições e, até mesmo, pelos próprios profissionais, de modo a permitir o desenvolvimento pessoal e o aperfeiçoamento de sua profissão. A formação tem como objetivo levar o profissional a sanar dificuldades e deficiências diagnosticadas na sua prática social ou aperfeiçoamento e enriquecimento da competência profissional (PAULA, 2009, p. 67).

Atenfelder (2005) explica que Educação permanente, Formação Continuada, educação continuada são termos que podem ser agrupados, pois são similares, ainda que com algumas peculiaridades que os caracterizam. Assim, a autora afirma que eles se complementam, em vez de se contradizerem, uma vez que todos têm no conhecimento o suporte para seu embasamento.

A Formação Continuada no Brasil constitui-se para Romanowski e Martins (2008) como um dos elementos de desenvolvimento dos professores, por complementar a Formação Inicial e permitir acesso a níveis mais elevados da carreira docente.

Porém, este termo não é novo, pois desde a década de 60, do século passado, que as Secretarias da Educação estruturaram programas de aperfeiçoamento profissional, para prover 
melhoria do desempenho nas escolas (PALMA FILHO, ALVES, 2003). Várias foram as iniciativas dos diferentes setores educacionais para que o professor fosse incentivado a retornar à universidade para atualização de conhecimentos por meio de cursos de longa ou pequena duração, sejam eles aperfeiçoamentos ou até cursos latu e strictu sensu (COSTA, 2004).

São definidas como ações de Formação Continuadas os congressos, os seminários, os simpósios, os colóquios, os encontros, as jornadas, os ciclos de falas, as palestras, os grupos de pesquisa, as oficinas, os cursos de extensão e/ou aperfeiçoamento, a pós-graduação lato sensu e a pós-graduação stricto sensu, sobre um conteúdo específico, realizado em escolas, instituições de Ensino Superior, ou outros espaços. Sendo que cada proposta atende a diferentes necessidades e interesses dos professores, contribuindo com o desenvolvimento profissional (PINTO, BARREIRO e SILVEIRA, 2010).

Todos estes cursos para Chimentão (2009) serviram para conscientizar os professores que teoria e prática são imbricadas. Visto que a primeira além de fundamentá-lo, ajuda-o a compreender melhor e significar a segunda.

E relevante destacar que durante muito tempo a Formação Continuada foi vista como sinônimo de cursos de pequena duração para cumprir uma exigência social, suprindo as lacunas da Formação Inicial, as quais conforme pontuam Alvarado Prada, Freitas e Freitas (2010) serviam apenas para sanar dificuldades do cotidiano escolar, campanha governamental e aquisição de certificados.

Entretanto, hoje ela é valorizada pela sociedade, e inclusive reconhecida pelo Governo Federal como uma necessidade, na LDBEN os artigos 13, 40, 44, 61, 63, 67, 70 e 87, atribuem à Formação Continuada como sendo um dever e direto dos professores, e papel do Estado, para assegurar as necessidades da qualificação docente (PINTO, BARREIRA e SILVEIRA, 2010).

Acompanhando as novas tendências da Formação Continuada, a Secretaria de Educação Básica - SEB do Ministério da Educação - MEC, propôs um catalogo de cursos tanto em nível de extensão como de aperfeiçoamento aos professores que atuam na Educação Básica para as universidades federais brasileiras. Entre estes, o de Docência na Educação Integral, vinculado ao Programa Mais Educação do MEC que tem como meta capacitar os professores para atuar na Educação Integral que é o mote da atual conjuntura do governo federal. 
A Educação Integral entendida não como a ampliação do tempo de permanência do aluno na escola, mas sim ter a possibilidade de agregar outras dimensões educativas como a afetiva, a moral, a esportiva e não apenas a cognitiva.

[...] uma educação que possibilite ao aluno uma atitude crítica e inteligente em situações reais de aprendizagem, não apenas teóricas, mas práticas; que persiga o desenvolvimento da criança em suas múltiplas dimensões: cognitiva, física, moral, ética, estética e social; que a escola seja esse espaço-tempo de vida, de prazer, de diálogo, de responsabilidade, de coerência entre o que se ensina e o que se faz; que seja problematizadora, possibilitando uma forma autêntica de pensar; que valorize o conhecimento de mundo dos alunos e os desafie para o querer "ser mais." (PONCE, BARROS NETO, 2013, p. 6).

A Universidade Federal do Triangulo Mineiro - UFTM, da cidade de Uberaba/MG, foi um dos polos selecionados para o oferecer o curso de Docência na Educação Integral/Mais Educação, presente no catálogo da SEB/MEC, em parceria com o Fundo Nacional de Desenvolvimento da Educação - FNDE. Assim, através da liderança de duas docentes dos cursos de graduação em Educação Física e em Letras, foi ofertado entre 2014 e 2015 o Curso de Aperfeiçoamento: Educação Integral: expressões verbais e corporais.

Considerando que o curso foi proposto aos professores da Educação Básica de Uberaba e região, este trabalho tem como objetivo caracterizar o perfil e verificar como ocorreu o interesse pelo curso de Aperfeiçoamento Educação Integral: Expressões verbais e corporais, oferecido pela Universidade Federal do Triângulo Mineiro - UFTM vinculado ao Programa Mais Educação da SEB/MEC.

\section{Caminhos da Pesquisa}

A investigação de natureza qualitativa e delineamento de estudo de caso (GIL, 1999), foi realizada junto ao participantes do Curso de Aperfeiçoamento em Docência na Escola de Tempo Integral Escola de Tempo Integral denominado Educação Integral: Expressões verbais e corporais, oferecido entre 2015 e 2015 pela Universidade Federal do Triângulo Mineiro - UFTM com o apoio da Prefeitura Municipal de Uberaba e do Ministério da Educação/ME via Secretaria de Educação Básica/SEB vinculado ao Programa Mais Educação. 
O mesmo foi desenvolvimento aos sábados com a duração de 6 horas, na própria universidade, através de módulos como: A Escola de Tempo Integral e as expressões corporais; Escrita, leitura e tempo integral; Multiletramento e as Tecnologias da Informação e Comunicação na Educação Integral; Literatura infanto-juvenil e leitura na Educação Integral, Expressões corporais e dança, Cultura popular e folclore, Jogos e Recreação na Educação Integral, Educação e patrimônio cultural, Esporte e Lazer na Educação Integral, além de um Seminários de Abertura e um de Encerramento, perfazendo o total de 180 horas $(64 \%$ em sistema de aula presencial e $36 \%$ em sistema não presencial).

O curso teve início 298 inscritos, sendo que para participar da pesquisa foram estabelecidos os seguintes critérios: 1. Estar regularmente matriculado no curso; 2. Estar presente na data da coleta; 3. Atuar na Educação Básica e 4. Concordar em participar da investigação assinando o Termo de Consentimento Livre e Esclarecido - TCLE.

Diante dos critérios estabelecidos foram selecionados 56 alunos.

Para a coleta de dados foi aplicado um questionário com as seguintes questões: 1 . Sexo; 2. Idade; 3. Formação; 4. Tempo de formação; 5. Participação em cursos de Formação Continuada e 6. Forma de ingresso no curso.

As respostas foram lidas e sistematizadas em uma planilha do Microsoft Office Excel, para análise do estudo, que foi realizada por meio da frequência descritiva.

\section{Quem são dos Docentes: resultados e discussão}

Em relação ao Sexo, apenas 2(4\%) eram do sexo masculino e 54 (96\%) do sexo feminino (Gráfico 1).

Gráfico 1 - Gênero dos participantes da pesquisa

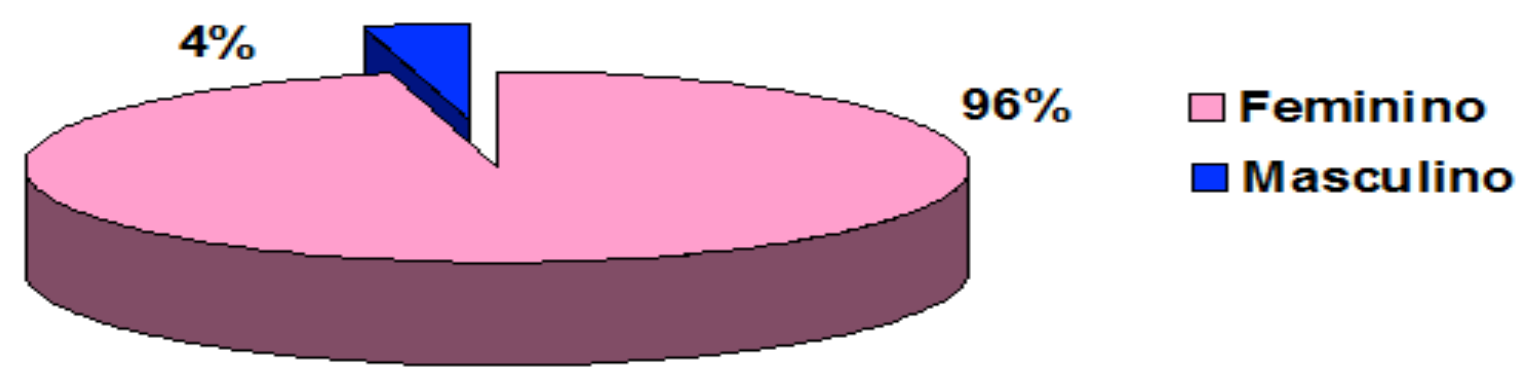


Fonte: Coleta de dados, 2014.

Este resultado nos leva a questionar se seria esse um indicador não somente de que há um predomínio do gênero feminino na educação, mas também de que são elas que estão buscando maiores níveis de escolaridade e de Formação Continuada?

A esse respeito Estevam e Guimarães (2011) destacam os dados do Instituto Nacional de Estudos e Pesquisas Educacionais - INEP, do ano de 2007, que investigou a participação das mulheres na docência, durante os anos de escolarização, em que salientam uma diferença entre gêneros crescente, sendo de somente $1 \%$ nas séries do Ensino Fundamental em detrimento de $13 \%$ na Graduação universitária.

No período anterior ao século XIX devido ao fato de somente os homens receberem, de acordo com Pereira (2014) escolarização, essa tarefa também era exercida exclusivamente por eles. Enquanto as mulheres eram proibidas de realizar atividades intelectuais, à elas eram destinados os compromissos domésticos, realizados no interior dos lares, como plantio, canto, bordados e cozinha.

Por esta razão Duraes (2012) afirma que o trabalho docente, mormente exercido por homens, especialmente, no Ensino Primário, começou a sofrer a evasão dos mesmos, a partir do século XIX. Momento em que a mulher começou a ter mais espaço nessa área, iniciando o processo de feminização da profissão, que de acordo com a autora, perdura até hoje. Dado que não aconteceu somente no Brasil, como também na Inglaterra, País de Gales, Estados Unidos, Espanha e Portugal.

Quanto a Idade dos participantes, há predominância entre 41 e 60 anos, ou seja: sete (13\%) sujeitos entre 20 à 30 anos; 15 (27\%) entre 31 à 40; $16(29 \%)$ entre 41 à 50 anos; 17 $(29 \%)$ entre 51 à 60 e apenas 1 (2\%) declarou ter mais de 60 anos de idade (Gráfico 2).

Gráfico 2 - Faixa etária dos participantes

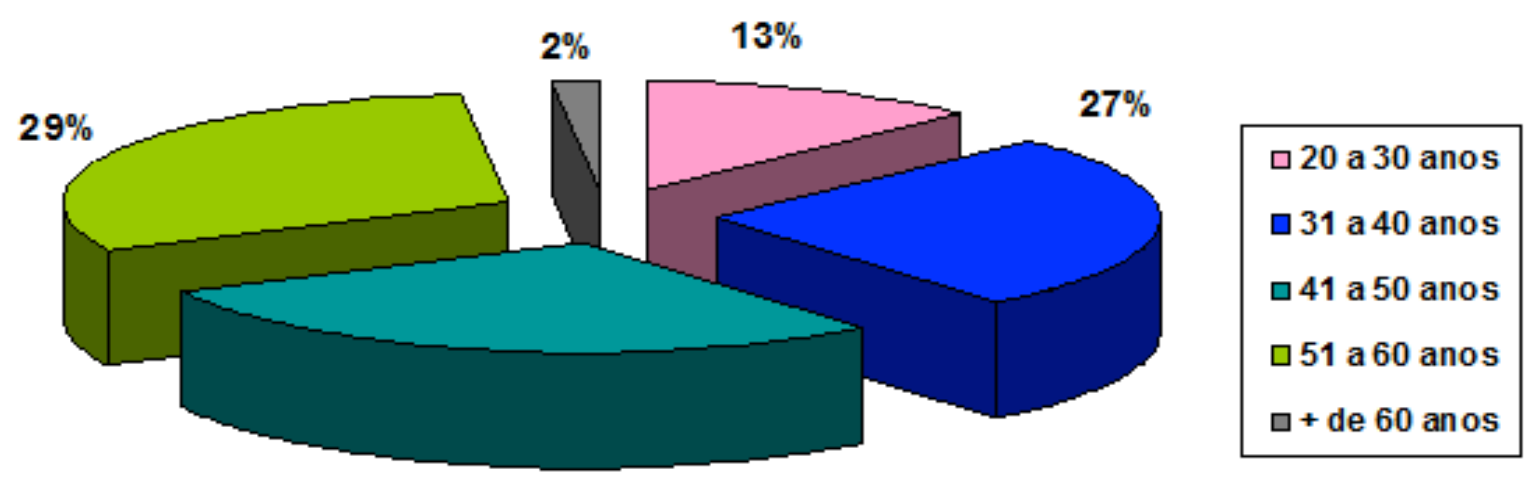

$29 \%$

http://www.uftm.edu.br/revistaeletronica 
Fonte: Coleta de dados, 2014.

De acordo com Gatti e Sá Barreto (2009) o perfil etário dos docentes possibilita-nos depreender alguns aspectos de sobre suas escolaridades, como o fato de que na Educação Infantil há predomínio de profissionais mais jovens, enquanto no Ensino Fundamental a quantidade de professores é proporcional de um quarto para cada faixa etária, em detrimento de maioria de profissionais mais velhos, entre 30 e 50 anos no Ensino Médio. As autoras ainda destacam que 21,6\% desses professores da Educação Básica prosseguem estudando, sobretudo os da Educação Infantil, o que converge que os dados da pesquisa aqui apresentada.

Estudos do DIEESE (2014) destacam que em 12 anos o número de professores na Educação Básica aumentou 32,9\%, principalmente após 2006. Os estudos mostram uma alteração significativa no perfil etário do docente nos últimos anos, sendo que em 2002, a maior parte dos ingressantes tinha até 35 anos de idade, preponderantemente até 25 anos. Em linhas gerais metade deles possuía entre 31 e 45 anos, e apenas 20,3\% tinha mais de 46 anos de idade.

O estudo contrapõe esses dados com os números de setembro de 2013, para evidenciar mudanças no perfil etário dos docentes tais quais: o professor está ingressando mais tarde na carreira docente, em menor número antes dos 25 anos do que em 2002, mas a maioria mantem-se menor de 35 anos de idade.

De acordo com os dados os profissionais aumentaram a permanência na carreira, com aumento de $11,2 \%$ de profissionais acima de 40 anos que continuam em atividade. $\mathrm{O}$ DIEESE (2014) justifica isso pela exigência legal, na Lei de Diretrizes Básicas da Educação Nacional (LDBEN), de formação superior para professores, reduzindo 49,98\% do número de profissionais com escolaridade até o Ensino Médio.

Analisando a Formação dos sujeitos investigados, percebemos que há diferentes áreas, uma vez que: 27 (48\%) são pedagogos (quatro têm mais de uma formação, de modo que, além da Pedagogia um é formado em Administração; outro em Estudos Sociais; outro História, Geografia e Filosofia, Ciências Sociais; um formado em História e Geografia), sendo ainda, cinco com o curso em andamento, ou seja, ainda não concluíram a formação; 12 (21\%) sujeitos possuem Magistério (destes um afirma ser formado em Magistério, Ciências Sociais e Jornalismo e outro em Magistério e Bacharel em Direito); sete (13\%) formados em Letras (sendo que um ainda não concluiu o curso); dois (4\%) em Educação Física; e, oito (14\%) não informaram a formação (Gráfico 3). 
Gráfico 3 - Áreas de formação acadêmica dos participantes
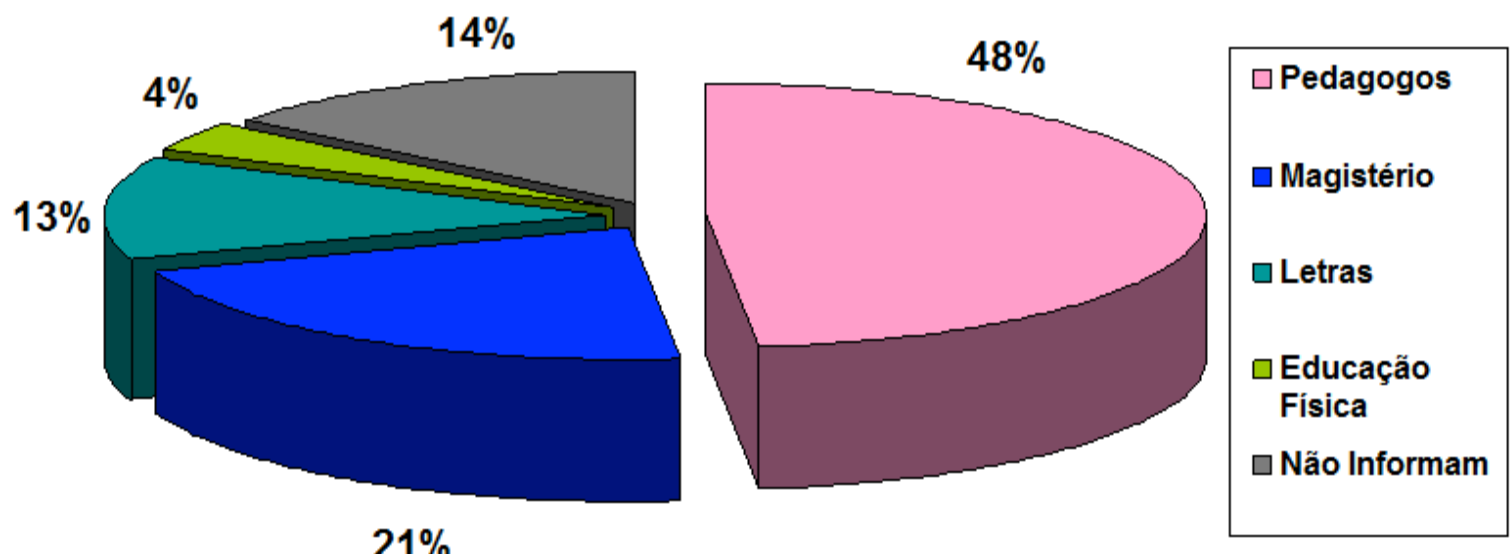

Fonte: Coleta de dados, 2014.

O resultado demonstra que diferentes são as realidades dos respondentes, quanto a sua profissão e que possibilidades diversas estão presentes no universo acadêmico o que tem feito que as pessoas possam ter mais de uma formação. Como podemos evidenciar a maior parte dos sujeitos que apresentam mais de uma formação, graduaram-se em áreas não educacionais, de modo que essas formações complementem suas ações, não mudem de área de atuação. Mas sim, que busquem no Ensino Superior o aperfeiçoamento de sua formação.

Rabelo (2013, p. 209) se dedicou a pesquisar as justificativas que homens e mulheres estão dando nas universidades para o ingresso na formação para a carreira docente e constatou que eles têm apresentado motivos semelhantes, como: "facilidade de estudo no curso de formação, entrada rápida no mercado de trabalho, alto índice de empregabilidade, entre outros". Todavia a fala de um diretor de curso de formação docente na pesquisa evidencia que para escolha profissional os homens priorizaram a empregabilidade e a possibilidade de transformação da sociedade em detrimento ao gosto por crianças, que se apresenta como um dos maiores valores explicitados pelas mulheres.

Apesar das diferentes formações, observamos que em relação ao Tempo de Formação, ela é recente, considerando principalmente a faixa etária. Os resultados apontados mostram que: três sujeitos (6\%) são formados há menos de um ano; 11 (21\%) há menos de cinco anos; oito (15\%) entre 6 e 10 anos de formados; sete (13\%) entre 11 e 15 anos; cinco 
(10\%) entre 16 e 20 anos; seis (12\%) entre 26 e 30 anos; três $(6 \%)$ formados há mais de 30 anos, e nove (17\%) dos sujeitos não informaram (Gráfico 4).

Gráfico 4 - Tempo de formação acadêmica dos participantes
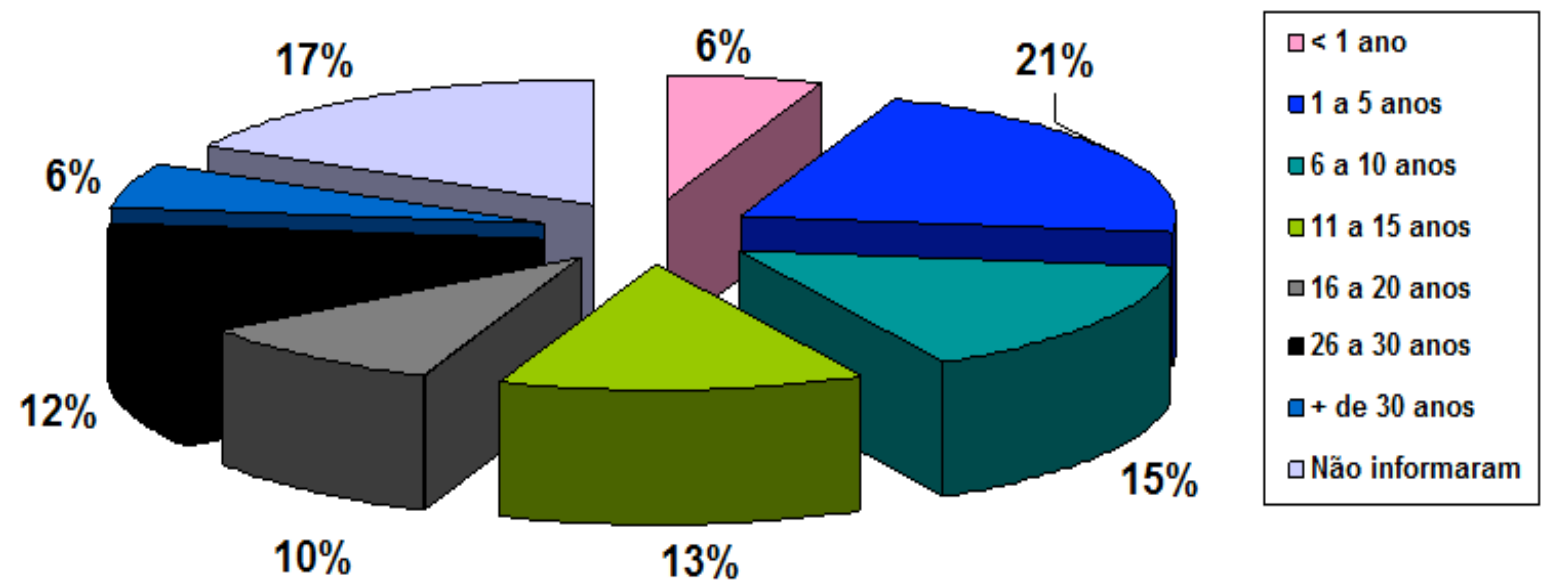

Fonte: Coleta de dados, 2014.

O resultado demonstra maior número de sujeitos formados em uma média de 10 anos, ou seja, posterior a LDBEN- Lei 9.394/96 que apregoava a formação superior para docência no Ensino Básico. A exigência da formação acadêmica deveu-se a adequação da classe, bem como o seu fortalecimento, pois se considerava o Magistério uma formação mínima para a preparação do professor para a sua atuação pedagógica.

Visto que em 1996 a aprovação da Lei de Diretrizes e Bases da Educação Nacional LDBEN no 9394/96, na qual uma das alterações é no Ensino Superior, a partir dela as instituições puderam assumir diferentes formatos como: universidades, centros universitários, faculdades integradas, faculdades e institutos superiores ou escolas superiores (BRASIL, 1996). Desse modo, ampliam-se o número de cursos de nível superior, inclusive de licenciaturas, até porque o artigo 62 da LDBEN n ${ }^{\text {0 }}$ 9394/96 propõe que a formação de docentes para atuar na Educação Básica seja feita em nível superior, incentivando esse crescimento.

Quando questionados sobre a Participação em Cursos de Formação 25 (45\%) afirmaram ser a primeira vez que realizam um curso de Formação Continuada; 31 (55\%) já participaram antes (Gráfico 5).

Gráfico 5 - Sobre a participação em Curso de Formação Continuada 


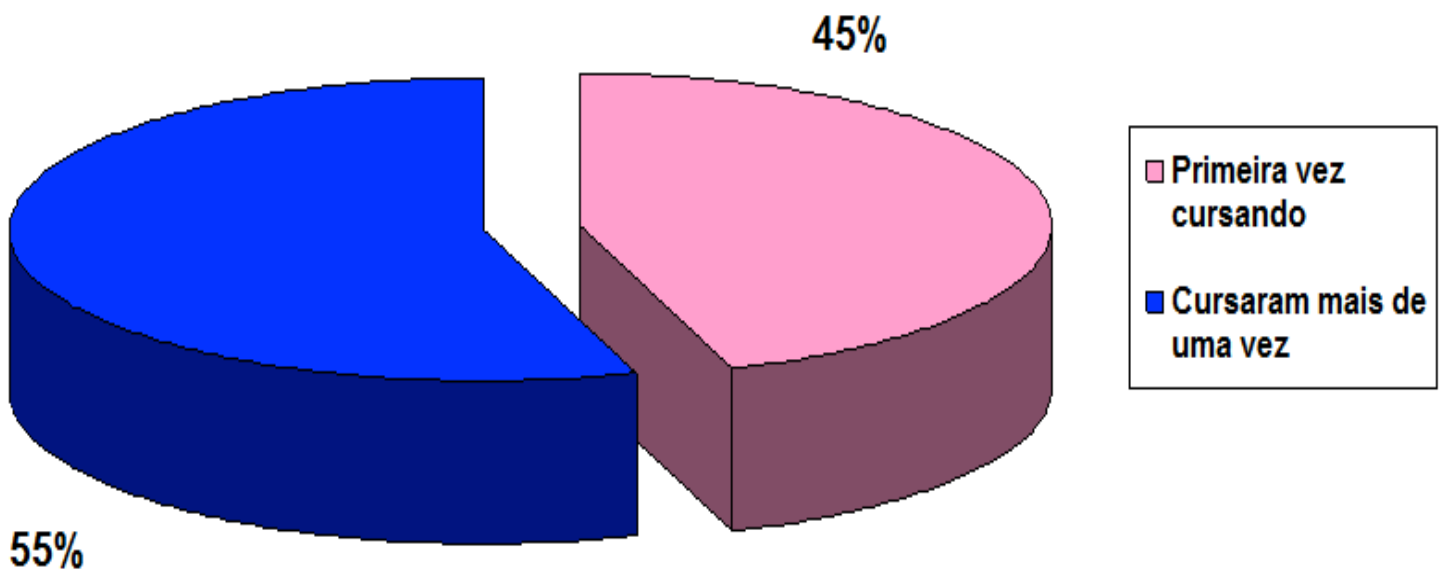

Fonte: Coleta de dados, 2014.

Dos que já participaram de cursos, alguns especificaram da seguinte forma: nove sujeitos disseram ter participado do curso do Mais Educação de 2013, e estavam cursando novamente; dois cursistas fizeram parte de cada um dos seguintes cursos Pro letramento Letramento e Alfabetização, Penaic, Renafor, Mesas Pedagógicas, Formação Continuada em serviço organizada pela Prefeitura Municipal de Uberaba; um cursista para cada um dos cursos: PROETe, Casa do Educador, Valores humanos e ambientais Agronelli, Proler, Estratégias de ensino, Trabalho com material concreto nas turmas iniciais; e um Curso oferecido pelo Colégio Cenecista José Ferreira em parceria com a Prefeitura; além de três sujeitos que afirmaram que participaram de várias ações sem especificar quais; e nove sujeitos que identificaram ter participado de Formação Continuada organizada pelas instituições em que atuam.

A procura dos professores por cursos de Formação Continuada tem sido uma ocorrência muito frequente. Como se observa na pesquisa, muitos não ficam em um curso apenas, procuram estar sempre se reciclando. Este é o espírito da Formação Continuada.

O professor atualizado tem consciência de que a Formação Continuada tem como função promover "O desenvolvimento das habilidades necessárias à condução com qualidade do processo pedagógico em sala de aula”. (ALBANO et al, 2010, p. 19). Por este motivo, fica evidente que em um curso somente, não se consegue atingir este objetivo com qualidade.

Perrenoud (2002, p. 206) ainda afirma que "A autoridade escolar provoca uma atualização, que consiste ao mesmo tempo em informação, explicação e formação". Desta forma, a própria realidade escolar conduz, mobilizando estes professores para a concretização da Formação Continuada. 
Sobre esse item é importante destacarmos que dos 31 sujeitos que já haviam participado de algum curso de Formação Continuada, nove realizaram o aperfeiçoamento do Programa Mais Educação, oferecido pela UFTM no ano anterior, ou seja, já ter feito parte uma vez não foi razão para que suprimissem uma segunda adesão no mesmo curso, o que indica uma satisfação e confiança no trabalho desenvolvido pelos organizadores do curso. $\mathrm{O}$ que nos permite inferir que embora o curso apresentasse alguns objetivos semelhantes ao do ofertado no ano anterior, os professores fizeram questão de cursá-lo novamente, para desfrutar das atividades que ali são disponibilizadas.

Acreditamos que essa busca não seja apenas por imposição das Secretarias de Educação, gestores ou por mero aumento salarial e acúmulos de certificados, mas sim por uma intenção pessoal de atualização. Concluímos isso tendo em vista professores com tanto pouco tempo de formado, ou seja, com os conteúdos e práticas recentemente qualificados, e até mesmo aqueles que estão muito próximos da aposentadoria, mas que ainda buscam qualificação.

Não podemos deixar de mencionar a importância e influência dos colegas sobre esse curso em específico ou cursos oferecidos pela UFTM, uma vez que parte deles informou que o incentivo e até mesmo propaganda positiva de colegas que já haviam participado ou desse curso ou de outros oferecidos pela UFTM auxiliou na escolha.

Também buscamos conhecer se o interesse do professor pelo curso foi espontâneo, por incentivo da instituição que trabalha ou por obrigação.

Os dados mostram que 45 (82\%) afirmaram que foi espontâneo; três $(6 \%)$ realizaram por incentivo de outros; dois (4\%) o fazem por obrigação; um (2\%) realiza o curso por todos os motivos (espontâneo, incentivado, obrigação); três (6\%) não informaram o motivo (Gráfico 6). 
Gráfico 6 - Fator motivador da realização da Formação Continuada
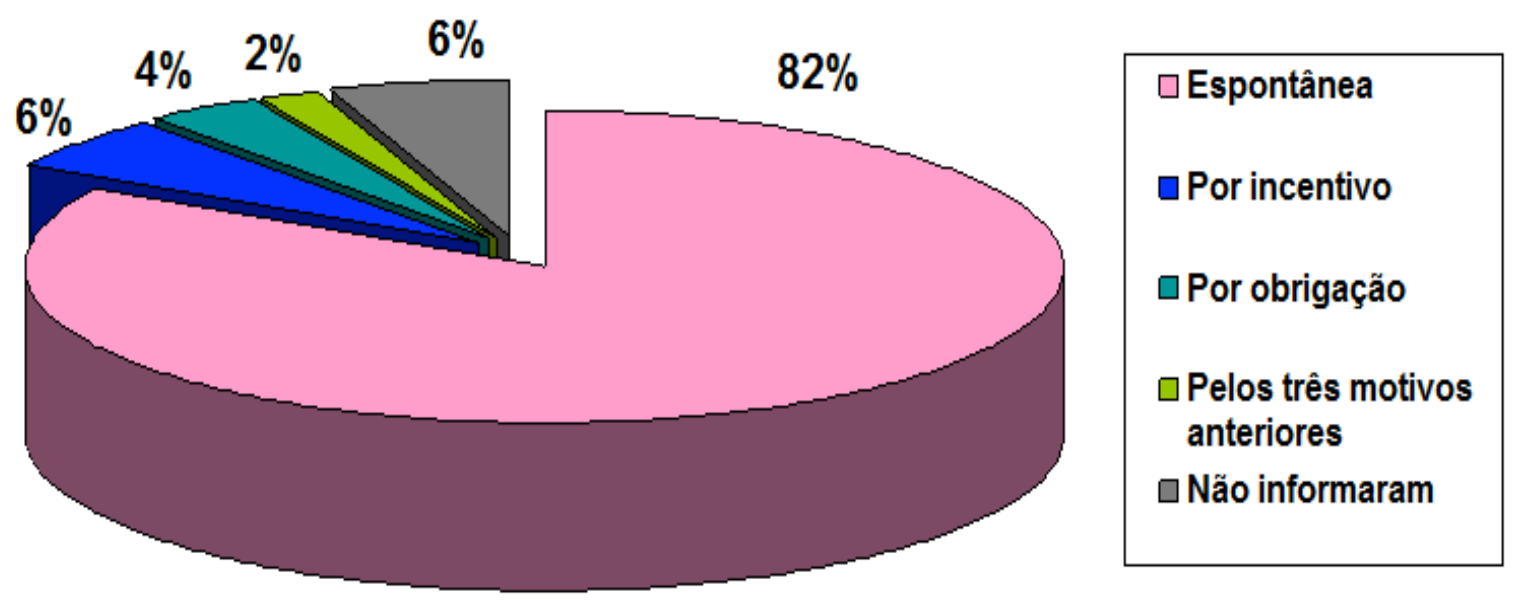

Fonte: Coleta de dados, 2014.

Neste aspecto, procurando dar maior esclarecimento das respostas, optamos por apresentar itens que explicitam a fala dos cursistas. Na Tabela 1, observa-se ainda, os motivos que foram dados para justificar a realização da Formação Continuada, marcados agora de forma categórica.

Tabela 1 - Justificativas da realização da Formação Continuada.

\begin{tabular}{|c|c|c|}
\hline \multicolumn{2}{|r|}{ Respostas e Justificativas } & Quantidade de sujeitos \\
\hline \multirow{4}{*}{3.} & 1. $\quad$ Espontânea & 24 \\
\hline & Espontânea por sempre participar & 4 \\
\hline & Espontânea por ter participado do ano anterior & 3 \\
\hline & $\begin{array}{l}\text { Espontânea e incentivo da instituição de } \\
\text { trabalho }\end{array}$ & 4 \\
\hline \multirow{2}{*}{ ( } & Espontânea e incentivo de colegas & 2 \\
\hline & Espontânea por ser ofertado pela UFTM & 1 \\
\hline 7. & $\begin{array}{c}\text { Espontânea por atuar em Escolas de Tempo } \\
\text { Integral }\end{array}$ & 1 \\
\hline \multirow[t]{6}{*}{$\begin{array}{l}8 . \\
9 .\end{array}$} & $\begin{array}{l}\text { Espontânea por interesse em Educação Integral } \\
\text { Espontânea para aprimorar conhecimentos para }\end{array}$ & 1 \\
\hline & os alunos & 7 \\
\hline & Incentivo da instituição de trabalho & 3 \\
\hline & 11. Obrigação & 2 \\
\hline & 12. Todos os motivos & 1 \\
\hline & 13. “Sim" e não informaram & 3 \\
\hline & Total & 56 \\
\hline
\end{tabular}

Fonte:Coleta de dados, 2014. 
Tozetto e Wengzynski (2012) ressalvam que o professor enquanto educador tem sua formação e prática permeada dos objetivos e intenções estabelecidos pela sociedade, cingida de crenças e valores históricos e culturais sobre as os saberes e ações por eles desenvolvidos. De modo que para as autoras a transformação de uma realidade ocorre pelas ações e manifestações realizadas pelos docentes.

As autoras defendem neste sentido, a Formação Continuada, como artifício que se baseia na prática, orientado pela teoria de novos e velhos conhecimentos, para promover mudanças e transformações, construídas individual ou coletivamente, ao longo do tempo.

Conforme já explicitamos nos referenciais que embasam esse trabalho, em tempo de constantes mudanças tornam-se prementes ações de Formação Continuada em busca de mudanças nas práticas dos docentes. Assim, é necessário além do incentivo das instituições, também a realização de ações desse tipo na escola, além da conscientização pessoal de cada profissional sobre essa necessidade.

Obter a resposta de que quase a unanimidade dos participantes ingressou no curso espontaneamente é um dado muito satisfatório, por indicar que as ações de incentivo a Formação Continuada têm surtido efeitos positivos nos professores, de modo que eles estejam buscando por iniciativa própria, e não somente por imposição ou vantagens financeiras.

Embora alguns enunciem que participaram apenas por incentivo ou obrigação, parte deles mostra satisfação com a participação, ao longo do curso, como evidenciamos na resposta do $S 50$ - "A princípio por obrigação, mas estou gostando muito do curso e aprendendo muito".

Destarte, o modo como se ingressa na Formação Continuada não é garantia do aproveitamento, pois questões complexas como autonomia, interesse e outras é que garantirão os resultados positivos da inserção nos cursos.

Um fato salientado por Santos (2007, p. 134) é que em virtude dos baixos salários os professores têm aceitado cursos mais baratos, que algumas vezes oferecem estruturas e qualidade suspeitas. Apesar de terem consciência, participam ainda sim, "em nome da competitividade e do individualismo implícitos pelas políticas públicas neoliberais", que visam o lucro, e não os avanços educacionais, é assim que segundo a autora, os diplomas são acumulados tendo em vista a quantidade e não a qualidade.

Ainda sobre os cursos a autora destaca que são intensificação do trabalho dos professores, para acima de tudo garantir que cumpram suas obrigações, em vez de mediar 
reflexões e questionamentos próprios e também sobre questões políticas, o que para ela é uma forma de manipular as concepções e práticas desses profissionais.

\section{À guisa de conclusões}

Este estudo se mostra como o ensejo para futuras pesquisas, principalmente sob a ótica da Formação Continuada, porém sugerimos que para além dos professores, seja ouvida toda a comunidade escolar que vivencia as ações do Programa Mais Educação.

Acreditamos que uma lacuna de nosso estudo foi o número reduzido de respondentes, considerando os matriculados. Isto se associa a falta de regularidade na frequência do curso não é constante, o que, talvez, possa ser sanado com aplicação de instrumentos ao longo do desenvolvimento do mesmo.

Os resultados foram muito satisfatórios, e revigoram nossas esperanças sobre o sistema escolar brasileiro, que carece tanto de valorização. Os ganhos são múltiplos com a Formação Continuada e sabe-se de sua importância, principalmente, do ponto de vista da preparação constante para a adequação de desafios, como se apresenta a educação em período integral.

Foi interessante confirmar a predominância feminina na docência, mesmo após diversas desmistificações sobre essa ser uma profissão feminina. Bem como foi satisfatório inferir que as políticas educacionais têm de fato garantido que a maior parte dos docentes sejam licenciados, e participem constantemente de ações de formação continuada.

Em vista dos resultados apresentados, concluímos que essas ações políticas, embora careçam de algumas melhorias e reformulações, tem apresentado indicativos positivos expressos por seus participantes, além de mudanças nas práticas desses profissionais, pela capacitação oferecida, o que beneficia toda a comunidade escolar.

Desse modo, pretendemos reiterar a necessidade de busca contínua por capacitação profissional, haja vista a precária formação inicial que alguns cursos oferecem, assim pretendemos com os relatos aqui apresentados promover o incentivo a autonomia para que esses profissionais busquem qualificação constante. 


\section{REFERÊNCIAS}

ALBANO, A. A. S.; BARBOZA, P. B.; CASTRO, P. V.; ZERO, M.A. A formação de professores para a Educação Básica na LDB e as Expectativas para a Educação do Futuro. Diálogos Pertinentes - Revista Científica de Letras. Franca (SP), v. 6, n. 2, p. 11-30, jul./dez. 2010

ALVARADO-PRADA, L. E.; FREITAS, T. C., FREITAS, C. A. Formação Continuada de Professores: Alguns Conceitos, Interesses, Necessidades e Propostas. Revista Diálogo Educacional, v. 10, p. 367-387, maio/ago. 2010.

ALTENFELDER, A. H. Desafios e tendências em Formação Continuada. Revista Construção Psicopedagogica, São Paulo, v. 13, n. 10, 2005.

BRASIL. Ministério da Educação. Lei 9394. Estabelece as Diretrizes da Educação Nacional. Brasília- DF: Ministério da Educação, 1996.

CHIMENTÃO, L. K. O significado da Formação Continuada Docente. $4^{\circ} \mathbf{C O N P E F}$

Congresso Norte Paranaense de Educação Física Escolar. -Londrina, Paraná, 2009.

Disponível em: $<$ htpps://www.uel.br/eventos/conpef/conpef4/objetivos.htm>. Acesso em: 20 set. 2014.

COSTA, N. M. L. A Formação Contínua de Professores - novas tendências e novos caminhos. Revista Holos, Ano 20, Dezembro de 2004, p. 63-75.

DIEESE. Transformações recentes no perfil do docente das escolas estaduais e municipais de educação básica. 2014. Disponível em:

http://www.dieese.org.br/notatecnica/2014/notaTec141DocentesPnadvf.pdf . Acessado em: 10 de outubro de 2015.

DURAES, S. J. A. Sobre algumas relações entre qualificação, trabalho docente e gênero.

Educação e Sociedade, Campinas , v. 33, n. 118, p. 271-288, Mar. 2012.

ESTEVAM, H. M.; GUIMARAES, S. Avaliação do perfil de egressos do programa de pósgraduação stricto sensu em educação da ufu: impacto na formação docente e de pesquisador (2004-2009). Revista Avaliação (Campinas), Sorocaba , v. 16, n. 3, p. 703-730, Nov. 2011.

GATTI, B. A.; SÁ BARRETO, E. S. Professores do Brasil: impasses e desafios. Brasília: UNESCO, 2009.

GIL, A.C. Métodos e técnicas de pesquisa social. São Paulo: Atlas, 1999.

IMBERNÓN, F. Formação Docente e Profissional: formar-se para a mudança e a incerteza. Tradução de Silvana Cobucci Leite. 7 ed. São Paulo: Cortez, 2009. 127 p.

PONTE, J. P. Da formação ao desenvolvimento profissional. Actas do ProfMa, Lisboa: APM, 1998. 
PALMA FILHO, J. C., \& ALVES, M. L. Formação Continuada: Memórias. Em: R. L. L. Barbosa (Org.) Formação de professores: desafios e perspectivas. São Paulo: Editora Unesp. p.279-296, 2003.

PAULA, S.G. Formação Continuada de professores: perspectivas atuais. Paideia r. do curso de pedagogia da Faculdade de Ciências Humanas e Sociais, Univ. Fumec Belo Horizonte Ano 6 n. 6 p. 65-86 jan./jun. 2009.

PEREIRA, M. R. O que quer uma professora?. Educação e Realidade. Porto Alegre. 39(1): 181-199, Mar. 2014.

PERRENOUD, P. Práticas Pedagógicas, profissão docente e formação: perspectiva sociológica. Lisboa: Dom Quixote, 2002.

PINTO, C. L. L.; BARREIRO, C. B.; SILVEIRA, D. N. Formação Continuada de professores: ampliando a compreensão acerca deste conceito. Revista Thema, v. 7, n.1, p.1$14,2010$.

PONCE, C. S.; BARROS NETA, M. A. P. Concepções de Educação Integral na Escola Pública de Sinop - MT: uma reflexão fenomenológica. In: 36 Reunião Nacional da ANPED, 2013, Goiânia-GO.Sistema Nacional de Educação e Participação Popular:Desafios para as Políticas Educacionais, 2013.

PONTE, J. P. Da formação ao desenvolvimento profissional. Actas do ProfMa, Lisboa: APM, 1998.

RABELO, A. Debates sobre gênero na docência: o professor do sexo masculino nas séries iniciais do Rio de Janeiro-Brasil e Aveiro-Portugal. Revista Educação. Curitiba, v.48, p. 207234, Jun. 2013.

ROMANOWSKI, J. P.; MARTINS, P. L. O. Formação Continuada: contribuição para o desenvolvimento profissional dos professores. In: ANPED Sul 2008- ANAIS VII Seminário de Pesquisa em Educação da Região Sul - Pesquisa e Inserção Social, 2008.

SANTOS, E. T. Formação de Professores: um direito que conduz à emancipação? Uma imposição que leva à alienação?. ETD- Educação Temática Digital, v. 8, n. 2, p. 126-142, jun. 2007.

SAVIANI, D. História das IdeiasPedagógicas no Brasil. 2 ed. Campinas: SP: Autores Associados, 2008.

SILVA, J. C. M.. Formação Continuada do Professores: visando a própria experiência para uma nova perspectiva. Minas Gerais: Revista Ibero-Americana de Educação, p. 1-11, 2011.

TEIXEIRA, F. S.; SILVA, M. J. A.; LIMA, M. G. O desenvolvimento docente na perspectiva da (auto) formação profissional - UFPI - PPGED - CCE - Teresina-PI. 2010. Disponível em:

$<$ htpps://www.ufpi.br/subsiteFiles/ppged/arquivos/files/VI.encontro.2010/GT.3/GT_03_09_2 010.pdf>. Acesso em: 20 abr. 2015. 
TOZETTO, S. S.; WENGZYNSKI, C. D. A Formação Continuada e as contribuições para a docência. In: Anais IX Anped Sul, 2012, Caxias do Sul. Seminário de Pesquisa em Educação da Região Sul. Caxias do Sul: Grafia Nordeste, 2012.

RECEBIDO EM: 10/03/2016

APROVADO PARA PUBLICAÇÃO EM: 29/11/2016 